\title{
Hallazgo incidental postrauma abdominal
}

\author{
Diana Marcela Rodríguez De La Hoz, Margareth Mendoza Álvarez, María Eugenia Orozco, \\ María De Vedia, Nicolás Roccatagliata, Ricardo Cobeñas, Nebil Larrañaga
}

Departamento de Diagnóstico por imágenes. Centro de Educación Médica e Investigaciones Clínicas (CEMIC).

Ciudad Autónoma de Buenos Aires, Argentina.

Acta Gastroenterol Latinoam 2021;51(2):164

Recibido: 15/12/2020 / Aceptado: 10/05/2021 / Publicado online: 21/06/2021 / https://doi.org/10.52787/xoro6319

\section{Presentación de caso}

Paciente femenina de 24 meses de edad, sin antecedentes de importancia, acude a la guardia por presentar trauma cerrado de abdomen, con el hallazgo en el examen físico de hepatomegalia. Se documentan valores iniciales de alfafetoproteína (AFP) en $42457 \mathrm{UI} / \mathrm{ml}$; HB: 9,8 g/dL; HTO: 30,3\%; leucocitos: $10340 \mathrm{~mm}^{3}$; TGO: $53 \mathrm{UI} / \mathrm{L}$; TGP: 11,1 UI/ml; LDH: $626 \mathrm{UH} / \mathrm{ml}$; y fosfatasa alcalina: $110 \mathrm{UI} / \mathrm{L}$. Se le realiza TCMD con contraste EV (Figuras 1 a 3).

Figura 1. A: Corte axial de la TCMD, sin contraste EV. Se observa una imagen de aspecto sólido, con aisladas calcificaciones, ubicada en la cavidad abdominal (asterisco). B: Corte axial de la TCMD, con contraste EV. Se reconoce una imagen sólida que realza en la fase arterial tras la administración del contraste EV (asterisco).
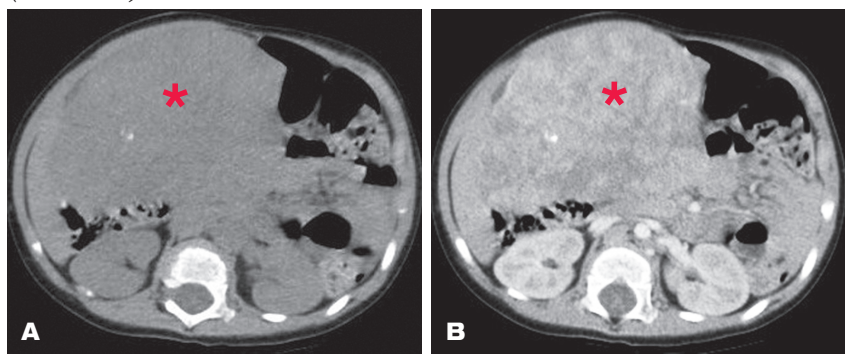

Correspondencia: Diana Marcela Rodríguez De La Hoz Correo electrónico: dimarcela11@gmail.com

\author{
Abreviaturas \\ HPB: Hepatoblastoma. \\ TCMD: Tomografia Computada Multidetector. \\ AFP: Alfafetoproteina. \\ $E V$ : Endovenoso. \\ HB: Hemoglobina. \\ HTO: Hematocrito. \\ TGP: Transaminasa glutámico-pirúvica. \\ TGO: Transaminasa glutámico-oxalacética. \\ LDH: Lactato deshidrogenasa.
}

Figura 2. Corte coronal de la TCMD, con contraste EV. Se observa una imagen sólida que contacta el lóbulo hepático izquierdo (flecha).

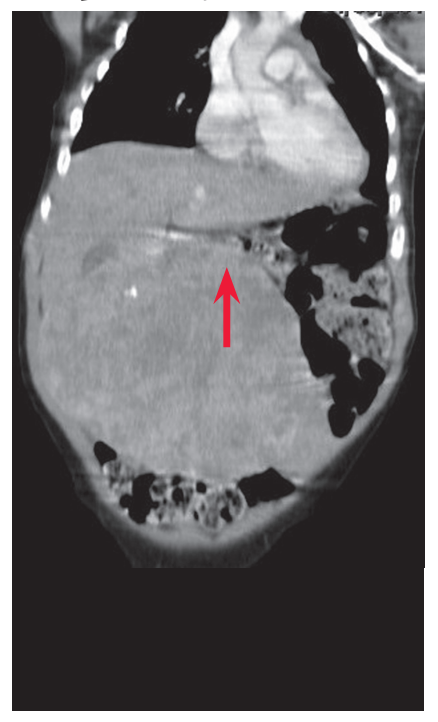

Figura 3. Corte sagital de la TCMD, con contraste EV. Hay una imagen sólida que produce un desplazamiento de las estructuras vecinas.

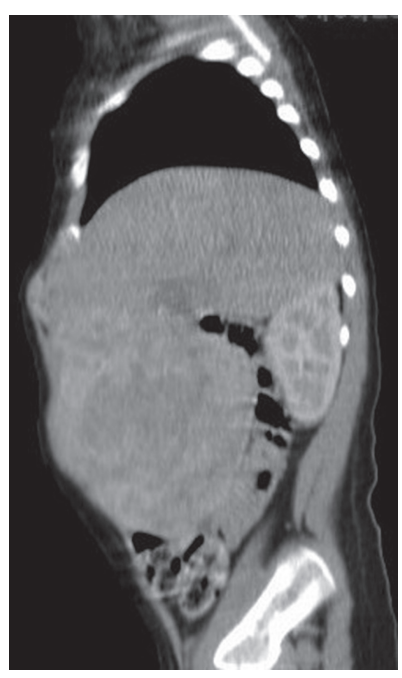

¿Cuál es su diagnóstico? Resolución del caso en la página 234 


\section{Solución del caso. Hallazgo incidental postrauma abdominal}

\section{Viene de la página 164}

Se consideró como un diagnóstico diferencial el carcinoma hepatocelular, teniendo en cuenta los niveles elevados de la AFP. En cuanto al grupo etario de este tumor, se presenta principalmente en los niños entre los 12 y 14 años de edad y, de forma menos frecuente, en los menores de 5 años. Se lo descartó en nuestro caso porque, adicionalmente, se tuvo en cuenta que no existía una condición hepática preexistente para sospechar este diagnóstico.

Desde el punto de vista imagenológico, se sospechó también un sarcoma embrionario indiferenciado, ya que este tumor se observa en la TCMD como una gran masa hipodensa con respecto al resto del parénquima hepático, que puede o no presentar calcificaciones y tabiques en su interior y ávido realce tras la administración de contraste debido al estroma mixoide que presenta. Para este caso, se descartó ya que en estos tumores típicamente la AFP y las pruebas de función hepática permanecen normales, de forma contraria a nuestro caso.

Epidemiológicamente, se consideró como diagnóstico el hamartoma mesenquimal, dado que es más común en la población pediátrica menor a los 3 años como en nuestro caso y de forma imagenológica se presenta como una gran masa abdominal, predominantemente quística con algunos tabiques internos, asociada de forma clásica a niveles normales de AFP. Sin embargo, estos hallazgos van en contra a la presentación del caso descripto.

El diagnóstico radiológico fue de hepatoblastoma (HBP) pretext II, con metástasis pulmonares. La conducta elegida fue tratamiento con quimioterapia (doxorrubicina/cisplatino), según el protocolo SIOPEL 4. Actualmente, se encuentra en seguimiento clínico e imagenológico, con una marcada reducción del tamaño de la lesión.

El hepatoblastoma es el tumor hepático maligno más frecuente en la edad pediátrica. Afecta sobre todo a los niños menores de 3 años, de forma predominante en el sexo masculino.

\section{Hepatoblastoma en edad pediátrica}

En Argentina, hasta el año 2016, el HBP representó el $1,4 \%$ del total de los cánceres pediátricos, con una sobrevida a 5 años de un $57 \% .^{1}$
En cuanto a la etiología, es aún desconocida. La edad de aparición sugiere la presencia de un componente genético. Se han descripto factores de riesgo y condiciones asociadas tales como: la prematuridad, el bajo peso al nacer, el síndrome de Aicardi, el síndrome de Beckwith-Wiedemann, la poliposis adenomatosa familiar, entre otros. ${ }^{2}$

Se presenta como una masa sólida que compromete algunos de los dos lóbulos hepáticos. Puede ser asintomática o manifestarse como un dolor abdominal inespecífico $y$, con menor frecuencia, pérdida de peso, hiporexia e ictericia. La enfermedad metastásica con mayor frecuencia afecta los pulmones, los huesos, el cerebro, los ganglios linfáticos y los ovarios. ${ }^{3}$

La AFP es el marcador de laboratorio más útil para el HPB. En el 90\% de los casos, se la detecta en altos niveles, los cuales a su vez sirven como marcador para monitorizar la respuesta al tratamiento y detectar su recurrencia. En otras ocasiones, se aumenta la secreción de gonadotropina coriónica humana $\beta{ }^{3}$

En el diagnóstico por imagen, el HPB aparece como un tumor bien circunscripto, puede ser lobulado y con tabiques en su interior.

La TCMD es el gold standard diagnóstico, donde se evidencia una masa circunscrita hipodensa en relación con el parénquima hepático, con la presencia de calcio en más del $50 \%$ de los casos, que muestra una captación lenta del contraste endovenoso en la fase temprana y homogeniza en tiempos tardíos. ${ }^{3-5}$

En cuanto al tratamiento, la resección quirúrgica constituye un factor fundamental, ya que a su vez determina el pronóstico de la enfermedad. Hasta un $60 \%$ de los HPB es irresecable en el momento del diagnóstico. No obstante, con el uso de la quimioterapia neoadyuvante, hasta el $85 \%$ se vuelve resecable. Para los casos que se consideran irresecables, existe la opción del trasplante hepático. Las lesiones metastásicas al pulmón no representan una contraindicación absoluta para el trasplante hepático, ya que son sensibles al tratamiento con quimioterapia. ${ }^{3}$

Sostén financiero. No posee. 
Aviso de derechos de autor

\section{(C) $(\mathbb{Q} \otimes(\odot)$}

(C) 2021 Acta Gastroenterológica Latinoamericana. Este es un artículo de acceso abierto publicado bajo los términos de la Licencia Creative Commons Attribution (CC BY-NC-SA 4.0), la cual permite el uso, la distribución y la reproducción de forma no comercial, siempre que se cite al autor y la fuente original.

Cite este artículo como: Rodriguez De La Hoz DM, Mendoza Álvarez M, Orozco ME y col. Hallazgo incidental postrauma abdominal. Acta Gastroenterol Latinoam. 2021;51(2):164, 234-5. https://doi.org/10.52787/xoro6319

\section{Referencias}

1. Moreno F, Chaplin MA. Registro oncopediátrico hospitalario argentino. 6a ed. Ciudad Autónoma de Buenos Aires: Instituto Nacional del Cáncer, 2018.

2. DeBaun MR, Tucker MA. Risk of cancer during the first four year of life in children from The Beckwith-Wiedermann Syndrome Registry. The Journal of Pediatrics. 1998;132:398-400.

3. Chung EM, Lattin GE Jr, Cube R, Lewis RB, Marichal-Hernández C, Shawhan R, Conran RM. From the Archives of the AFIP: Pediatric Liver Masses: Radiologic-Pathologic Correlation Part 2. Malignant Tumors. RadioGraphics. 2011;31(2):483-507.

4. Shamir SB, Kurian J, Kogan-Liberman D, Taragin BH. Hepatic imaging in neonates and young infants: State of the Art. Radiology. 2017;285(3):763-77.

5. García Ortega AA, Paredes Martínez ML, Fernández Hernández C, Serrano García C, Doménech Abellán E, Gilabert Úbeda A. Masas hepáticas sólidas en la infancia. Seram. 2014;S-0485:1-40. 